\title{
Impact of Friction Stir Welding on the Microstructure and Microtexture of Ferritic- Martensitic HT9 Steel
}

\author{
L.N. Brewer, L.L. Ray, and E.S.K. Menon \\ Mechanical and Aerospace Engineering Department, Naval Postgraduate School, Monterey, CA, USA
}

Ferritic-martensitic steels are a key material class for structural components in both fission and fusion reactors. Joining components using fusion welding; however, can create problems including material softening, residual stresses, porosity, etc. Friction stir welding (FSW) has been shown as an effective joining mechanism for a host of engineering materials including, more recently, some steels.[1] The processing-microstructure relationships for high chromium, ferritic-martensitic steels have not yet been established. In particular, the effect of varying FSW parameters on the evolution of microstructure has not been addressed. In this research, electron backscatter diffraction (EBSD) and optical microscopy were used to characterize the impact of FSW upon the microstructure of a modified HT9 steel for three different welding conditions of increasing heat input.

A modified HT9 ferritic-martensitic (FM) steel (Fe-12.0Cr-1.9W-0.5Mn-0.0.5C) was friction stir welded with three levels of tool rotational speed (300,350, and 400 RPM) at a fixed tool traverse speed $(50.8 \mathrm{~mm} / \mathrm{min})$. All three of these conditions produced fully consolidated, defect free welds; the microstructures of which were analyzed by optical microscopy and EBSD. Cross sections across the weld path were prepared by standard metallographic techniques and electropolishing. Samples for optical microscopy were etched using a solution of $20 \mathrm{ml} \mathrm{H}_{2} \mathrm{O}, 20 \mathrm{~mL} \mathrm{HNO}_{3}, 20 \mathrm{ml} \mathrm{HCl}$, and $10 \mathrm{ml} \mathrm{HF}$. EBSD analyses were completed using a Zeiss Neon 40 scanning electron microscope at $20 \mathrm{keV}$ beam voltage, $60 \mu \mathrm{m}$ objective aperture, and a probe current of $1 \mathrm{nA}$. The EBSD signal was collected and analyzed using the EDAX OIM 6.0 software with a Hikari high speed camera.

The microstructure of friction stir welded material closely resembled that of the base FM steel. The basic microstructure of the rolled plate HT9A was comprised of long (several hundred micron) ferrite platelets with regions of finer-sized (micron) martensite in between platelets (Figure 1A). The ferrite platelets were highly elongated and extended in the rolling direction of the material. The center of the stir zone, for each FSW condition, possessed the same, basic microstructure: ferrite platelets with martensitic regions in between platelets (Figure 1B-D). With increasing rotational tool speed, small, but distinct, changes in the stir zone microstructure were observed. As the rotational speed increased, the high angle grain boundaries in the ferrite platelets were no longer perpendicular to the platelet axis. In addition, the lenticular shape of the martensitic grains observed in the base plate, evolved towards a more equiaxed shape as the rotation tool speed increased. The ferrite grain size within the platelets was reduced significantly after FSW: from $27 \mu \mathrm{m}$ in the base plate to $14 \mu \mathrm{m}$ in the stir zone of the $300-\mathrm{RPM}$ condition. The FSW process, for all conditions, did not significantly alter the martensite grain size.

The microtexture after FSW maintained the $\{\mathrm{hkl}\}<111>$ - partial fiber texture observed in the base plate, albeit at a weaker intensity for all welding conditions. The pole figures represent data from both the ferrite platelets and the martensitic grains; however, there are many more martensitic grains, so they represent most of the intensity observed in the pole figures. This texture is quite similar to those observed for torsion testing of interstitial free steels[2] and in FSW for other ferritic steels[3]. 

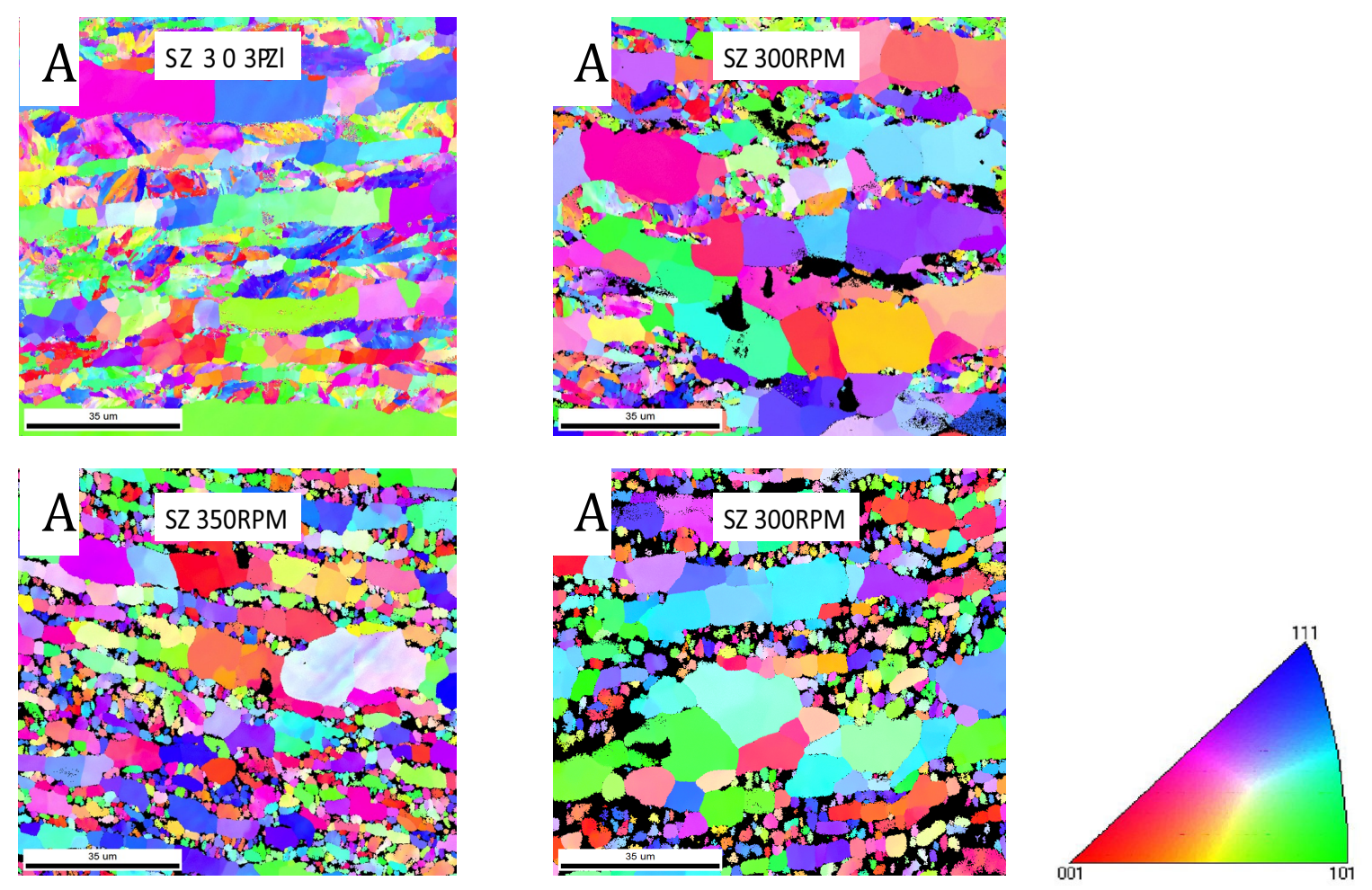

Figure 1. Inverse pole figure maps (with respect to the welding direction) for the stir zone as a function of toll rotation speed. The scale bar is 35 microns.

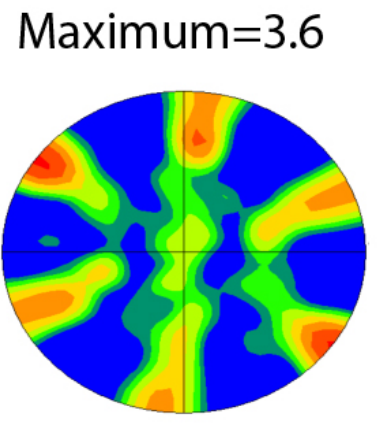

Base F-M Steel

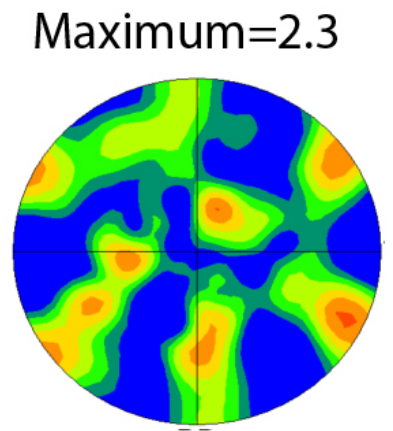

300 RPM
Maximum $=2.3$

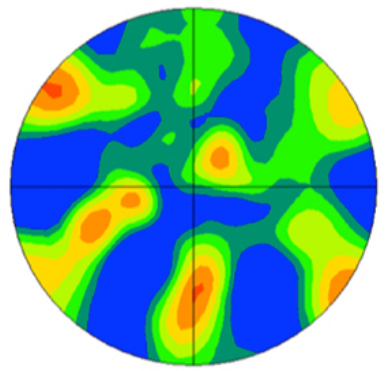

350 RPM

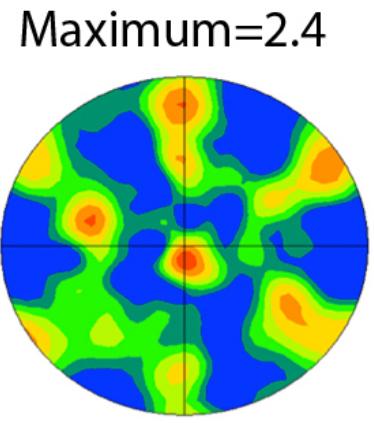

400 RPM

Figure 2. EBSD pole figures (normal to welding direction, transverse direction to the right)

This work in part was performed under the auspices of the U.S. Department of Energy by Lawrence Livermore National Laboratory under Contract DE-AC52-07NA27344.

\section{References:}

[1] G. Cam, "Friction Stir Welded Structural Materials: beyond Al- Alloys," International Materials Reviews, vol. 56, pp. 1-48, 2011.

[2] J. Baczynski and J. J. Jonas, "Torsion textures produced by dynamic recrystallization in $\mathrm{E} \pm$-iron and two interstitial-free steels," Metallurgical and Materials Transactions A, vol. 29, pp. 447-462, 1998.

[3] W. Han, S. Ukai, F. Wan, Y. Sato, B. Leng, H. Numata, N. Oono, S. Hayashi, Q. Tang, and Y. Sugino, "Hardness and Micro-Texture in Friction Stir Welds of a Nanostructured Oxide Dispersion Strengthened Ferritic Steel," Materials Transactions, vol. 53, pp. 390-394, 2012. 